\title{
Unresectable Metastasis
}

National Cancer Institute

\section{Source}

National Cancer Institute. Unresectable Metastasis. NCI Thesaurus. Code C148309.

A finding indicating that a metastatic tumor is not amenable to surgical resection. 